\title{
PICK1 regulates the trafficking of ASIC1a and acidotoxicity in a BAR domain lipid binding- dependent manner
}

\author{
Wenying Jin ${ }^{1}$, Chong Shen ${ }^{1,2}$, Lan Jing ${ }^{3,4}$, Xiang-ming Zha ${ }^{3}$, Jun Xia ${ }^{1 *}$
}

\begin{abstract}
Background: Acid-sensing ion channel 1a (ASIC1a) is the major ASIC subunit determining acid-activated currents in brain neurons. Recent studies show that ASIC1a play critical roles in acid-induced cell toxicity. While these studies raise the importance of ASIC1a in diseases, mechanisms for ASIC1a trafficking are not well understood. Interestingly, ASIC1a interacts with PICK1 (protein interacting with C-kinase 1), an intracellular protein that regulates trafficking of several membrane proteins. However, whether PICK1 regulates ASIC1a surface expression remains unknown.

Results: Here, we show that PICK1 overexpression increases ASIC1a surface level. A BAR domain mutant of PICK1, which impairs its lipid binding capability, blocks this increase. Lipid binding of PICK1 is also required for PICK1induced clustering of ASIC1a. Consistent with the effect on ASIC1a surface levels, PICK1 increases ASIC1a-mediated acidotoxicity and this effect requires both the PDZ and BAR domains of PICK1.
\end{abstract}

Conclusions: Taken together, our results indicate that PICK1 regulates trafficking and function of ASIC1a in a lipid binding-dependent manner.

\section{Background}

Acid-sensing ion channels (ASICs) are a group of cation channels that are activated by a decrease in extracellular $\mathrm{pH}[1,2]$. Four ASIC genes (ACCN1-4) have been identified, with ASIC1 and ASIC2 each has two splice variants (a and b). Each ASIC subunit contains two transmembrane domains with both $\mathrm{N}$ - and $\mathrm{C}$-termini reside inside the cell and a large cysteine-rich extracellular domain. Recent crystal structure shows that ASICs are trimers [3].

ASICs are predominantly expressed in the nervous system. In the central nervous system, ASIC1a is the major subunit determining acid-activated responses in neurons [4,5]. ASIC1a localizes to dendritic spines and regulates acid-induced $\mathrm{Ca}^{2+}$ increase in spines [6,7]. ASIC1a contributes to synaptic plasticity, learning and fear [5,8-10]. More importantly, ASIC1a plays critical roles in multiple neurological diseases including ischemia [11,12], multiple sclerosis [13], Parkinson's disease

\footnotetext{
* Correspondence: jxia@ust.hk

'Division of Life Science, The Hong Kong University of Science and

Technology, Clear Water Bay, Kowloon, Hong Kong, China

Full list of author information is available at the end of the article
}

[14], seizure [15], and pain [16,17]. These studies demonstrate the importance of ASIC1a in diseases. Several studies have examined the modulation of ASIC1a channel activity by redox reagents, divalent ions, and peptides [18-24]. However, molecular mechanism regulating ASIC1a trafficking is not well understood.

PICK1 (protein interacting with C kinase 1) is a scaffolding protein that regulates trafficking of multiple membrane proteins [25]. For example, interaction of PICK1 with GluR2, an AMPA-type glutamate receptor subunit, is important for synaptic targeting and surface expression of AMPA receptors during synaptic plasticity [26-33]. PICK1 also regulates vesicle trafficking between Golgi and acrosome in spermatids and deficiency of PICK1 in mice leads to abnormal acrosome formation and male infertility [34]. Two domains of PICK1 are important for its function. Its PDZ (PSD-95/Dlg/ZO-1) domain mediates direct interaction with many proteins that contain a PDZ binding motif. In addition to the PDZ domain, the middle portion of PICK1 contains a BAR (Bin/amphiphysin/Rvs) domain [35], which directly binds to lipids, mainly phosphoinositols [36]. Both the

\section{C) Biomed Central}


PDZ and BAR domains work together and enable PICK1 to couple its PDZ domain-binding partners (e.g. GluR2) to protein trafficking machinery [36,37].

Previous studies show that ASIC1a interacts with PICK1 and this interaction changes the subcellular clustering of ASIC1a $[38,39]$. The interaction of ASIC1a and PICK1 is mediated by the C-terminus of ASIC1a and the PDZ domain of PICK1. Furthermore, the interaction of PICK1 with ASIC1a was found to be regulated by protein kinases $[40,41]$. However, whether PICK1 regulates ASIC1a trafficking remains unknown.

Given that PICK1 regulates trafficking of several membrane proteins, and that PICK1 directly interacts with ASIC1, we hypothesize here that PDZ and BAR domains of PICK1 cooperatively regulate ASIC1a surface expression. Our results showed that PICK1 regulates cell-surface expression of ASIC1a in a lipid bindingdependent manner. Further, we showed that this interaction regulates acidosis-induced cell toxicity.

\section{Results}

\section{PICK1 regulates surface levels of ASIC1a}

As an ion channel, the number of ASIC1a at cell surface will determine the magnitude of ASIC1a-mediated response. To examine if PICK1 regulates the level of ASIC1a at cell surface, we performed cell surface protein biotinylation assay to measure the surface level of human ASIC1a. ASIC1a or ASIC1a with PICK1 were transfected into HEK293T cells. Surface proteins were labeled with membrane-impermeable biotin and then precipitated from cell lysates with immobilized NeutrAvidin beads. Surface and total samples were subjected to Western blot analysis. Figure 1A shows the validation of an ASIC1a antibody, which was directed against the C-terminal 61 amino acids of ASIC1a. As shown in Figure $1 \mathrm{~B}$, PICK1 significantly increases surface expression of ASIC1a. To obtain a quantitative measurement of PICK1's effect on surface ASIC1a, we normalized surface ASIC1a to total ASIC1a and obtained the ratio of ASIC1a at cell surface. This was done by loading different amounts of total ASIC1a to obtain a standard curve. The amount of surface ASIC1a was calculated by fitting the intensity of the surface ASIC1a to the standard curve. As shown in Figure $1 \mathrm{C}$, we found that there was $5.05 \% \pm 0.9 \%$ of ASIC1a located at cell surface. Coexpressing with PICK1 increased ASIC1a surface/total ratio to $7.80 \% \pm 1.4 \%(\mathrm{n}=5, \mathrm{p}<0.01$, paired $t$-test $)$.

We also noticed that there were multiple species of ASIC1a on the gel. To answer if this effect is specific to human ASIC1a, we studied mouse ASIC1a. Coexpressing of PICK1 with mouse ASIC1a also increased the population of faster migrating ASIC1a (Figure 1D). Previous studies show that differential glycosylation leads to the formation of multiple species of ASIC1a with different apparent molecular weights on western blots $[9,42]$. To assess if glycosylation results in the difference observed here, we treated ASIC1a transfected lysates with PNGase F, which removes all N-glycan, or EndoH, which removes high-mannose $\mathrm{N}$-glycans that are added early in the secretory pathway $[42,43]$. PNGase treatment reduced all slower migrating species to the faster migrating species in both control and PICK1 overexpressing conditions. In contrast, there was still a fraction of slow migrating species after EndoH treatment. These data suggest that PICK1 regulates the glycosylation and/or maturation of ASIC1a.

\section{PICK1-regulated surface expression of ASIC1a is} dependent on the lipid binding of PICK1's BAR domain

The BAR domain of PICK1 binds to lipids and this lipid binding regulates surface expression of AMPA receptors [36]. We therefore asked whether the effect of PICK1 on ASIC1a surface expression is also dependent on the BAR domain of PICK1. PICK1 2K-E is a lipid bindingdeficient mutant with two critical residues of the BAR domain, Lys266 and Lys268, mutated to glutamate [36]. Unlike the wild-type PICK1, PICK1 2K-E did not increase surface levels of ASIC1a (surface/total ASIC1a ratio: ASIC1a alone: $5.05 \% \pm 0.9 \%$; ASIC1a + PICK1: $7.80 \% \pm 1.4 \%$; ASIC1a + PICK1 2K-E: $5.18 \% \pm 1.6 \%$, $\mathrm{n}=5$, Figure $1 C$ ). This result indicates that lipid binding is required for PICK1-regulated surface expression of ASIC1a.

To test if PICK1's effect on ASIC1a surface expression requires their interaction, we also examined the effect of a PICK1 PDZ domain mutant, KD-AA, which has two critical residues in the PDZ domain of PICK1, Lys27 and Asp28, mutated to alanine and renders the mutated PICK1 unable to interact with ASIC1a [38,39]. As expected, PICK1 KD-AA had no effect on ASIC1a surface levels (surface ASIC1a ratio with PICK1 KA-AA: $5.42 \% \pm 1.6 \%, \mathrm{p}<0.05$ comparing to ASIC1a + PICK1, not significant comparing to ASIC1a alone or ASIC1a + PICK1 $2 \mathrm{~K}-\mathrm{E}, \mathrm{n}=4$, Figure $1 \mathrm{C}$ ). These results indicate that both the PDZ and BAR domains are required for PICK1 to regulate ASIC1a surface expression.

\section{Lipid binding is required for PICK1-induced clustering of ASIC1a}

Next, we asked whether lipid binding of PICK1 affects ASIC1a subcellular localization. We co-transfected ASIC1a with wild-type PICK1 or BAR-domain mutant PICK1 2K-E into HEK293T cells. When expressed alone in $293 \mathrm{~T}$ cells, ASIC1a was diffusely localized in cytosol with a pattern typical of membrane proteins. Similarly, wild-type PICK1 and PICK1 2K-E were also diffusely localized in cytosol (Figure 2A). When ASIC1a and wild-type PICK1 were co-transfected into 293T cells, 


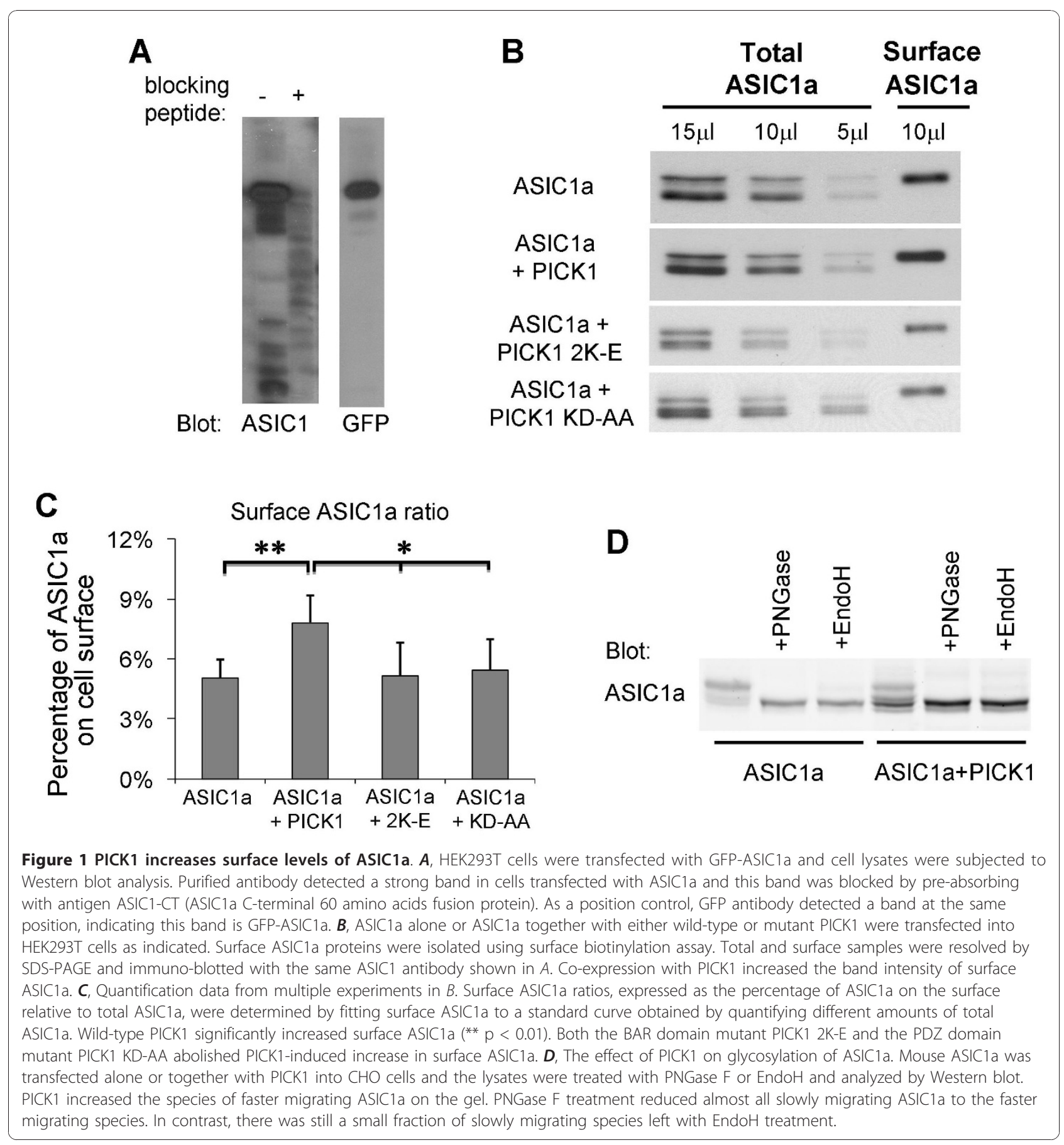

they formed co-clusters in the perinuclear region (Figure $2 \mathrm{~B}$, upper panel). This localization pattern is similar to what has been reported for PICK1 and ASIC2 [38,39]. One interesting phenomenon we observed was that ASIC1a and PICK1 also formed co-clusters along some cellular protrusions (Figure 2B, lower panel). The nature of these co-clusters is not clear at the moment. In contrast to wild-type PICK1, when PICK 2K-E mutant was co-transfected with ASIC1a in 293T cells, we did not observe any cluster formation (Figure $2 \mathrm{C}$ ). This result indicates that PICK1 requires its lipid binding ability to regulate the subcellular localization of ASIC1a.

To answer the question whether mutating the BAR domain of PICK1 interferes with its interaction with ASIC1a, we performed co-immunoprecipitation analysis. GFP-ASIC1a was co-transfected with myc-tagged wildtype or mutant PICK1 into HEK293T cells and immunoprecipitated with an anti-myc antibody. Consistent 


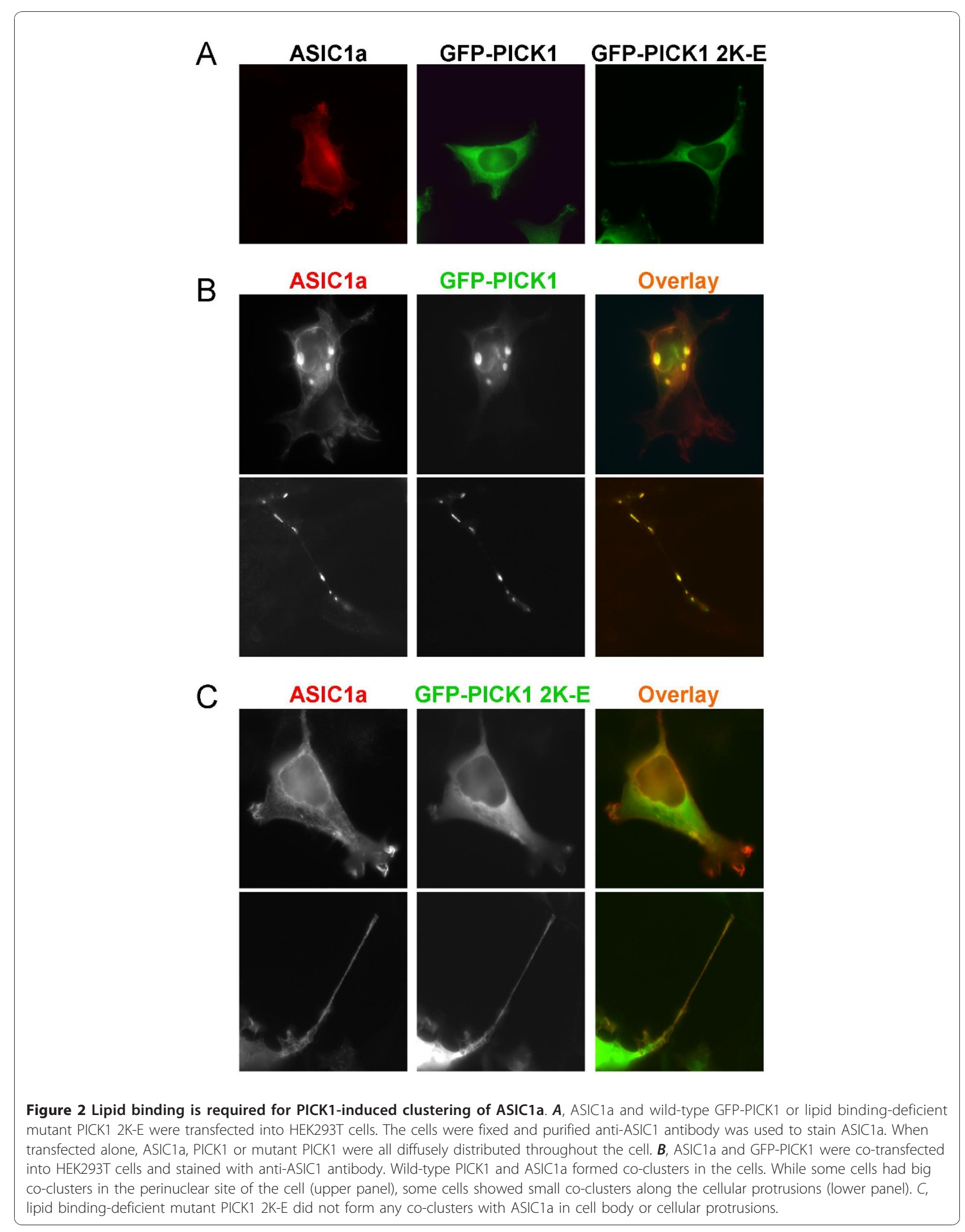




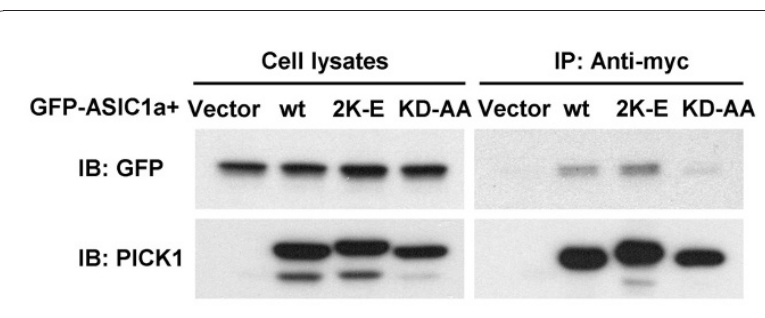

Figure 3 BAR domain mutant PICK1 2K-E still interacts with ASIC1a. HEK293T cells were transfected with GFP-ASIC1a together with myc-tagged wild-type PICK1, PICK1 2K-E, PICK1 KD-AA or the vector control, as indicated on the top. Cell lysates were immunoprecipitated with an anti-myc antibody and immunoblotted with either a GFP or a PICK1 antibody as indicated. The BAR domain mutant PICK1 2K-E Co-immunoprecipitated with ASIC1a similar to wild-type PICK1 but the PDZ mutant PICK1 KD-AA could not coimmunoprecipitate with ASICla.

with earlier studies [38,39], the PDZ domain mutant KD-AA greatly reduced its association with ASIC1a. In contrast, PICK1 2K-E had no effect on ASIC1a:PICK1 interaction (Figure 3). These results suggest that the BAR domain is not required for PICK1 to interact with ASIC1a but is necessary for it to cluster ASIC1a.

\section{PICK1 regulates ASIC1a-mediated acidotoxicity in a lipid-binding dependent manner}

To gain insight into the functional significance of PICK1-regulated trafficking of ASIC1a, we examined PICK1's role in acidosis-induced cell toxicity. We transfected ASIC1a, with or without PICK1, into COS7 cells. Forty eight hours after transfection, cells were treated with pH7.4 or pH6.0 solution for 2, 4 or 6 hours. We then quantified the percentage of cells that show condensed nuclei, a marker for apoptotic cell death. Similar to earlier reports $[11,44,45]$, we found that ASIC1a overexpression significantly increased cell death upon acid treatment (ASIC1a transfected cells: $145.8 \% \pm 14.8 \%$, $164.6 \% \pm 8.9 \%, 187.0 \% \pm 12.8 \%$ for $2,4,6$ hours respectively. $\mathrm{n}=7,{ }^{*} \mathrm{p}<0.05,{ }^{* * *} \mathrm{p}<0.01$ compared to control groups, Figure 4). Co-expression of PICK1 with ASIC1a further increased acidosis-induced cell death (ASIC1a + PICK1 transfected cells: $155.0 \% \pm 11.4 \%, 192.0 \% \pm 9.0 \%$, $244.0 \% \pm 16.6 \%$ for $2,4,6$ hours respectively. $\mathrm{n}=10$, *** $\mathrm{p}<0.01, * * \mathrm{p}<0.001$ compared to control groups; * $\mathrm{p}<0.05$ when compared with ASIC1a-transfected cells, Figure 4). In contrast, in non-transfected cells or PICK1-only transfected cells, pH6 solution treatment did not significantly affect cell viability (non-transfected cells: $104.5 \% \pm 10.0 \%, 100.8 \% \pm 15.8 \%, 99.0 \% \pm 12.3 \%$ for 2, 4, 6 hours respectively; PICK1-transfected cells: $90.2 \% \pm 14.0 \%, 104.4 \% \pm 16.5 \%, 103.0 \% \pm 17.1 \%$ for 2 , 4, 6 hours respectively. $n=5$, Figure 4 ). These results indicate that PICK1 does not increase acidotoxicity by itself. Instead, it increases the acidotoxicity mediated by ASIC1a by increasing the level of ASIC1a at cell surface.

Both the PDZ and BAR domains are required for PICK1's effect on surface expression of ASIC1a, we therefore asked if the PDZ and BAR domain mutants abolish the potentiation effect of PICK1 on acid-induced cell death. As expected, when co-expressed with ASIC1a, both PICK1 2K-E (ASIC1a + PICK1 2K-E: $126.9 \% \pm 7.8 \%, 141.5 \% \pm 10.7 \%, 164.0 \% \pm 9.6 \%$ for 2,4 , 6 hours respectively. $\mathrm{N}=6$, ** $\mathrm{p}<0.01$, **** $\mathrm{p}<0.001$ compared to wild-type PICK1 and ASIC1a co-transfected groups, Figure 5) and PICK1 KD-AA had significantly lower death rate comparing to wild-type PICK1 (ASIC1a + PICK1 KD-AA: $115.9 \% \pm 5.8 \%, 144.3 \% \pm$ $8.0 \%, 164.7 \% \pm 4.7 \%$ for $2,4,6$ hours respectively, $\mathrm{n}=6$, ** $\mathrm{p}<0.01,{ }^{* * * *} \mathrm{p}<0.001$ compared to wild-type PICK1 and ASIC1a co-transfected groups, Figure 5). These data indicate that PICK1 enhanced ASIC1a-mediated cell toxicity and this enhancement is dependent on PICK1's lipid binding ability and its interaction with ASIC1a.

\section{Discussion}

ASIC1a-mediated acidotoxicity has emerged as an important concept for understanding the mechanism of brain injury in multiple disease paradigms [46,47]. Our result that PICK1 increases surface levels of ASICla and ASIC1a-mediated acidotoxicity provides an interesting way to regulate ASIC1a in acid-induced cell toxicity. The findings here may lead to potential means to alter surface levels of ASIC1a and subsequently, acid-induced cell toxicity.

PICK1 interacts with ASICs and this interaction was proposed to regulate the function of ASICs [38-41]. However, little is known about the mechanism of the regulation. Our results here provide the first evidence that two domains (the BAR and PDZ domain) within PICK1 cooperatively regulate ASIC1a, and consequently its surface expression. Consistent with earlier results [38,39], a direct interaction between PICK1 and ASIC1a through the PDZ interaction is important. In addition, and similar to our earlier studies on AMPA receptors [36], the effect of PICK1 on ASIC1a localization and surface also requires the lipid binding of PICK1. When the BAR domain of PICK1 was mutated, it can no longer induce ASIC1a clustering or change its surface levels, although the interaction between the two proteins was unaffected.

These findings provide a mechanistic understanding of PICK1's role on ASIC1a trafficking and acidosis-induced cell death. It is possible to change surface levels of ASIC1a and thus ASIC1a-mediated acidotoxicity, by perturbing either the protein-protein interaction or protein-lipid interaction, for instance, via protein kinase or lipid kinase pathways. In fact, protein kinase A was 


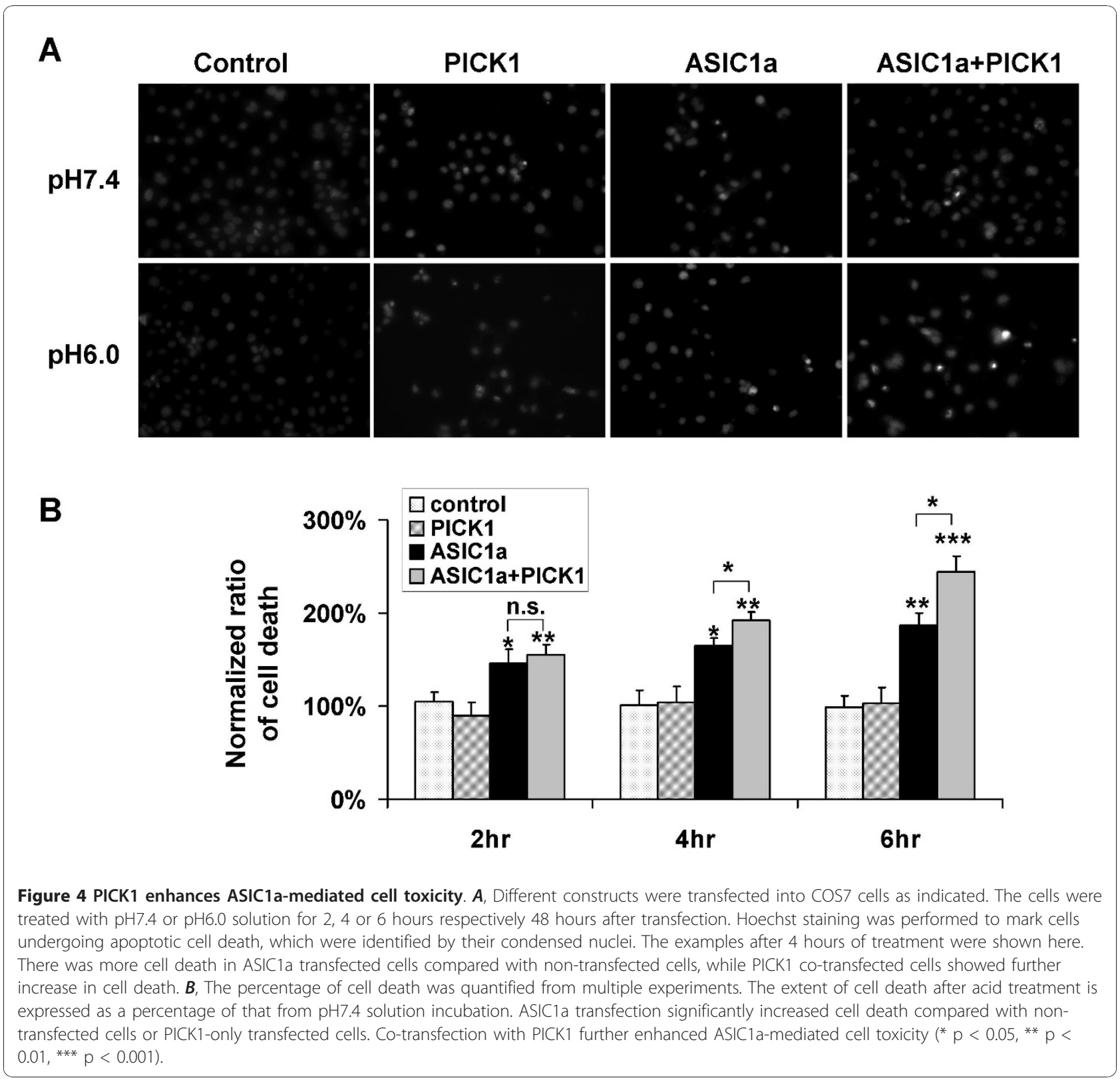

reported to phosphorylate ASIC1a and inhibit its interaction with PICK1 [41], while protein kinase C was reported to enhance ASIC2a-mediated current via PICK1 [40]. Of note, the major lipid molecules that bind to PICK1 are phosphoinositides, which are dynamically modified by lipid kinase and phosphatase on the cell membrane [36]. It would be interesting to test whether these protein kinases/phosphatases or lipid kinases/phosphatases play any role in ASIC1a trafficking and/or acidotoxicity.

In addition to PICK1, a number of other PDZ domaincontaining proteins have been found to interact with
ASICs. A multivalent PDZ domain containingprotein CIPP (channel-interacting PDZ domain protein) was found to interact with ASIC3 and overexpression of CIPP potentials ASIC3-mediated currents [48]. This potentiation is also likely due to increased surface expression of ASIC3. PSD-95 and several other PDZ domaincontaining proteins including Lin-7b, MAGI-1b and PIST were also found to interact with ASIC2a and ASIC3 [6,39]. While PSD-95 decreased surface ASIC3 and ASIC3mediated currents, Lin-7b increased surface ASIC3 and ASIC3-mediated current. These results, together with ours, suggest that it could be a general mechanism for 


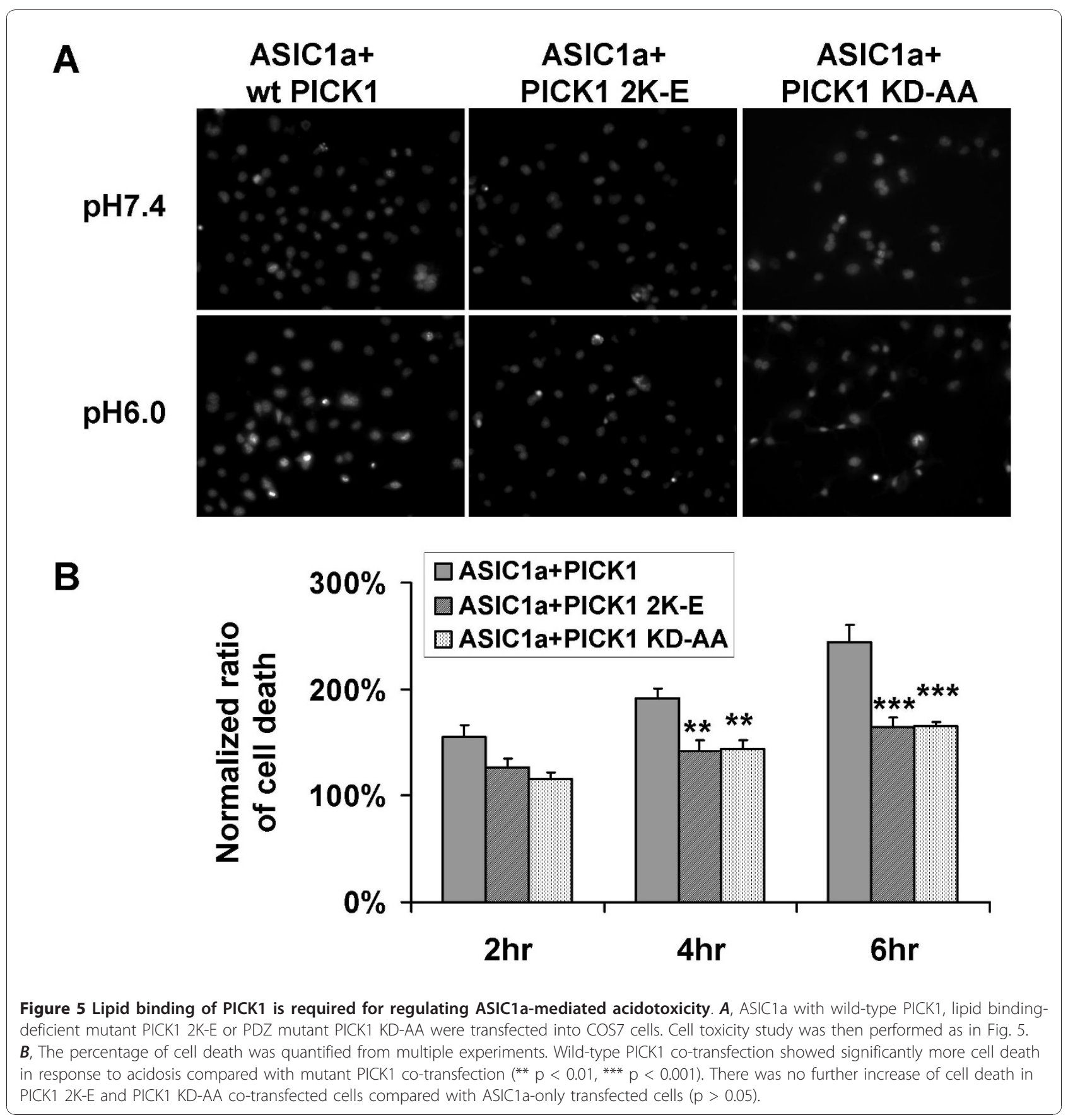

PDZ domain-containing proteins to regulate surface expression and subcellular targeting of ASICs. Interestingly, while previous studies show that ASIC1a is present in dendritic spines and enriches in synaptosomal preparations [5,6], the mechanisms for synaptic targeting of ASIC1a remain unclear. In two reports, ASIC1a did not coIP with PSD-95 $[6,49]$. Our results here may provide one possible mechanism for regulating ASIC1a targeting to synapses. It will be interesting to address the question if manipulating PICK1 changes ASIC1a synaptic localization in the future.

Previous studies have shown that PICK1 regulates multiple neuronal receptors/transporters. Similar to what is reported here, PICK1 increases surface dopamine transporters (DATs) and enhances DAT uptake [50]. In contrast, overexpression of PICK1 decreases surface expression of AMPA receptors [31,33,36,51] and netrin-1 receptor $\mathrm{UNC} 5 \mathrm{H} 1$ [52]. The detailed 
mechanism of PICK1-mediated protein trafficking is not clear at this moment. One model which could reconcile these differences is that PICK1 may maintain an intracellular reserve pool of membrane proteins. This pool of membrane proteins will engage in exchanging with cell surface proteins in a regulated manner. Consistent with this speculation, knockout of PICK1 leads to deficiency in both the insertion of GluR2 to cell surface of cerebellar stellate cells [28] and the removal of GluR2 from cell surface of cerebellar Purkinje neurons [27]. Upon stimulation, PICK1 can facilitate either endocytosis or exocytosis of its binding partners, depending on the distribution of these proteins in different pools and the nature of the stimulation. While the detailed mechanisms need more clarification, these findings suggest that PICK1 is a common protein trafficking regulator that couples membrane proteins to trafficking machinery via its unique combination of the PDZ domain and BAR domain.

\section{Methods}

\section{cDNA cloning, mutagenesis and protein purification}

Rat PICK1 cDNAs [26] and human ASIC1a (long form [38], kindly provided by Dr. Garcia-Anoveros and Dr. Corey) constructs were subcloned into corresponding expression vectors in frame by restriction enzyme digestion and ligation. Mouse ASIC1a expression constructs have been described earlier $[7,24]$. To generate BAR domain mutants of PICK1, we synthesized PCR (polymerase chain reaction) primers containing the desired mutation. PCR mutagenesis was performed using a Quikchange site-directed mutagenesis kit (Stratagene, La Jolla, CA, USA). All constructs were subsequently confirmed by sequencing. To produce fusion proteins, cDNA constructs were transformed into Escherichia Coli BL21 cells and induced with IPTG (isopropyl-beta-D-thiogalactopyranoside). GST (glutathione $\mathrm{S}$ transferase) fusion proteins were affinity-purified by glutathione-Sepharose-4B (Amersham Biosciences, Uppsala, Sweden) and His fusion protein was affinity-purified by $\mathrm{Ni}^{2+}$ chelate resin nickel-nitrilotriacetic acid (Qiagen, Valencia, CA, USA), according to the manufacturers' instructions. Purified fusion proteins were eluted and dialyzed against the corresponding buffers for follow-up experiments. Fusion protein concentrations were determined by Coomassie assays (Pierce, Rockford, IL, USA).

\section{ASIC1 antibody}

An anti-ASIC1 antibody was generated by injecting rabbits with a bacterially expressed GST fusion protein containing the amino acids 513-574 of human ASIC1a. Antiserum was purified by passing through Affi-Gel 10 (Bio-Rad, Richmond, CA, USA) that was coupled to His tagged C-terminal ASIC1a fusion protein (containing amino acids 513-574), washing with Tris-buffered saline (TBS, pH7.4), eluting with $100 \mathrm{mM}$ glycine- $\mathrm{HCl} \mathrm{pH} \mathrm{2.8,}$ and neutralizing with TBS (pH 8.0). A rabbit anti-ASIC1 antibody was kindly provided by Dr. John Wemmie and has been described earlier [10].

\section{Cell culture, transfection and immunostaining}

Human embryonic kidney (HEK) 293T cells or monkey kidney cells (COS7) were cultured in MEM (modified Eagle's Medium) media (Invitrogen-Gibco, Grand Island, NY, USA) plus fetal bovine serum. For immunostaining, HEK293T cells were grown on coverslips coated with $0.2 \%$ gelatin. cDNA constructs were transfected into the HEK293T cells by calcium phosphate co-precipitation. The cells were fixed 36-48 hours after transfection by $4 \%$ paraformaldehyde and $4 \%$ sucrose in phosphate-buffered saline (PBS) for 20 minutes at room temperature. The cells were then permeabilized by $0.2 \%$ Triton X-100 in PBS for 10 minutes at room temperature. After blocking with 10\% normal donkey serum (NDS) in PBS for 1 hour, the cells were incubated with affinity-purified rabbit anti-ASIC1 antibody in 3\% NDS for 1 hour at room temperature, followed by 1 hour of incubation with Red$\mathrm{X}$ conjugated fluorescence anti-rabbit secondary antibody (Jackson Immunoresearch; West Grove, PA, USA). After washing with PBS, the coverslips were mounted with Permafluor (Immunon, Pittsburgh, PA, USA). The cells were observed with a Nikon Eclipse TE2000 (Nikon Co., Tokyo, Japan) inverted fluorescence microscope under a 60x Plan Apochromatic oil lens (NA = 1.4, Nikon Co.). Pictures were taken by a monochrome low noise cooled CCD camera (SPOT-RT, Diagnostic Instruments, Sterling Heights, MI, USA) controlled by Metamorph imaging acquisition software (Universal Imaging, West Chester, PA, USA). Images were processed with Adobe Photoshop to adjust intensity and contrast, to select the region of interest and to overlay two images. All images were taken in monochrome gray scale and artificially colored for presentation.

\section{Co-immunoprecipitation}

GFP-tagged human ASIC1a were co-transfected into HEK293T cells with myc-PICK1, myc-PICK1 2K-E or myc-PICK1 KD-AA. Two days after transfection, the 293 T cells were lysed with $2 \%$ Triton X-100 in PBS and incubated with anti-myc antibody/Protein A complex at $4^{\circ} \mathrm{C}$ for at least 2 hours. The resin was washed once with cold PBS and 1\% Triton X-100, twice with cold PBS, $1 \%$ Triton $\mathrm{X}-100$ and $500 \mathrm{mM} \mathrm{NaCl}$ and three times with cold PBS. After washing, the resin was eluted with $1 \times$ SDS (sodium dodecyl sulphate) sample buffer and was analyzed by SDS-PAGE (SDS polyacrylamide gel electrophoresis) and immuno-blotted with affinitypurified rabbit anti-GFP or PICK1 antibody. 


\section{Biotinylation assay}

HEK293T cells were washed three times with phosphate-buffered saline supplemented with $0.5 \mathrm{mM} \mathrm{CaCl}_{2}$ and $0.5 \mathrm{mM} \mathrm{MgCl}_{2}$ (B buffer) and treated with $0.5 \mathrm{mg} /$ $\mathrm{ml}$ sulfo-succinimidyl-6-(biotinamido) hexanoate (sulfoNHS-LC-biotin from Pierce) in B buffer for 5 minutes at room temperature. The free sulfo-NHS-LC-biotin was removed by rapidly washing the cells two times with $100 \mathrm{mM}$ glycine in B buffer followed by two washes with B buffer. The biotinylated cells were solubilized with $1 \mathrm{ml}$ RIPA buffer (10 mM Tris, pH 7.4, $150 \mathrm{mM}$ $\mathrm{NaCl}, 1 \mathrm{mM}$ EDTA, 0.1\% SDS, 1\% Triton X-100, 1\% sodium deoxycholate). The samples were centrifuged at maxi-speed in a table-centrifuge for 15 minutes at $4{ }^{\circ} \mathrm{C}$. A sample of this supernatant was removed for estimation of the total protein. The remaining supernatant proteins were incubated with $100 \mu \mathrm{l} 50 \%$ slurry of NeutrAvidin beads (Pierce) for 1 hour at $4^{\circ} \mathrm{C}$ with constant rotation. After several washes, the biotinylated surface proteins were eluted from the NeutrAvidin beads in 100 $\mu \mathrm{l}$ of $1 \times$ SDS sample buffer. The samples were subjected to SDS-PAGE and Western blot analysis.

\section{Hoechst staining}

ASIC1a and myc-PICK1 were transfected into COS7 cells using lipofectamine 2000 (Invitrogen). Forty eight hours after transfection, the cells were incubated in a HEPES buffer (10 mM HEPES, $10 \mathrm{mM}$ glucose, 140 $\mathrm{mM} \mathrm{NaCl}, 5 \mathrm{mM} \mathrm{KCl}, 2 \mathrm{mM} \mathrm{CaCl}$, $0.8 \mathrm{mM} \mathrm{MgCl}_{2}$ ) with pH7.4 or pH6.0 for different times. Chromatin condensation was detected by nucleus staining with Hoechst 33342. Briefly, cultured cells were washed once with PBS and fixed with $4 \%$ paraformaldehyde plus $4 \%$ sucrose in PBS for 15 minutes at room temperature. The cells were then stained with Hoechst $33342(5 \mu \mathrm{g} /$ $\mathrm{ml}$ ) for 15 minutes at room temperature and washed twice with PBS. The nuclei were visualized under a fluorescence microscope at $20 \times$ magnification. The percentages of cell death were first calculated for each group and then normalized to the group incubated with pH7.4 solution. The extent of cell death after acid treatment was expressed as a percentage of the group that incubated with $\mathrm{pH} 7.4$ solution at the same time.

\section{PNGase and EndoH treatment and western blot analysis} Culture and lipofectamine 2000-mediated transfection of Chinese hamster oocyte $(\mathrm{CHO})$ cells (purchased from ATCC) were done as described earlier [24]. Mouse ASIC1a was co-transfected with eGFP or GFP-PICK1. Two days after transfection, cells were scraped off in PBS containing $1 \% \mathrm{NP} 40$ and $0.5 \% \mathrm{SDS}$ in the presence of protease inhibitors (Roche). Cell lysates were homogenized by brief sonication and cleared by centrifugation. For deglycosylation, cell lysates were boiled for $10 \mathrm{~min}$ at $100^{\circ} \mathrm{C}$ in $1 \times$ glycoprotein denaturing buffer (supplied by the manufacture), followed by adding $1.5 \mu \mathrm{l}$ of PNGase F (= $11.5 \mathrm{mU}$, New England Biolabs) or $1 \mu \mathrm{l}$ of Endo H (= $50 \mathrm{mU}$, New England Biolabs) to $50 \mu \mathrm{l}$ of lysate, and incubated overnight at $37^{\circ} \mathrm{C}$. Untreated and treated lysates were analyzed by western blot, using an Odyssey imaging system (LiCor) as described earlier [24].

\section{Statistics}

Student $t$ test was used for statistics unless otherwise specified.

\section{List of abbreviations}

ASIC: acid-sensing ionic channel; AMPA: alpha-amino-3-hydroxy-5-methyl-4isoxazole propionate; BAR domain, Bin/Amphiphysin/Rvs domain; CaMKII: $\mathrm{Ca}^{2}$ +/calmodulin-dependent protein kinase II; CIPP: channel-interacting PDZ domain-containing protein; DAT: dopamine transporter; DMSO: dimethyl sulfoxide; ENaC/DEG: epithelial $\mathrm{Na}^{+}$channel/degenerin; GST: glutathione S transferase; HEK293 cells: human embryonic kidney 293 cells; IPTG: isopropylbeta-D-thiogalactopyranoside; MEM: modified Eagle's medium; NDS: normal donkey serum; NMDAR: N-methyl-D-aspartate receptor; PBS: phosphate buffered saline; PCR: polymerase chain reaction; PICK1: protein interacting with C kinase 1; SDS: sodium dodecyl sulphate; SDS-PAGE: SDS polyacrylamide gel electrophoresis; TBS: Tris-buffered saline; TPA: tissue plasminogen activator.

\section{Acknowledgements}

We thank W. Tung and C. He for their excellent technical assistance; Dr. H Jun and Dr. Y. Fan's for their kind suggestions on our experiments. The work described in this paper was supported in part by grants from the Research Grants Council of Hong Kong, China (N_HKUST621/04, 663107, N_HKUST605/07, HKUST6/CRF/08), the National Basic Research Program of China (2010CB912002) and startup fund from University of South Alabama, USA.

\section{Author details}

'Division of Life Science, The Hong Kong University of Science and Technology, Clear Water Bay, Kowloon, Hong Kong, China. ${ }^{2}$ Department of Neurobiology, Institute of Neuroscience, Zhejiang University School of Medicine, 388 Yu Hang-tang Road, Hangzhou, Zhejiang 310058, China. ${ }^{3}$ Department of Cell Biology and Neuroscience, University of South Alabama College of Medicine, Mobile, AL 36688, USA. ${ }^{4}$ State Key Lab of New Drug \& Pharmaceutical Process, Shanghai Institute of Pharmaceutical Industry, 1320 West Beijing Rd, Shanghai 200040, China.

\section{Authors' contributions}

WJ, CS and LJ performed the experiments and analyzed data, XMZ and JX participated in the design, data analysis and coordination of the study, WJ, CS, XMZ and JX wrote the manuscript. All authors read and approved the final manuscript.

\section{Competing interests}

The authors declare that they have no competing interests.

Received: 13 December 2010 Accepted: 21 December 2010 Published: 21 December 2010

\section{References}

1. Wemmie JA, Price MP, Welsh MJ: Acid-sensing ion channels: advances, questions and therapeutic opportunities. Trends Neurosci 2006, 29:578-587.

2. Waldmann R, Champigny G, Lingueglia E, De Weille JR, Heurteaux C, Lazdunski M: H(+)-gated cation channels. Ann N Y Acad Sci 1999 868:67-76. 
3. Jasti J, Furukawa H, Gonzales EB, Gouaux E: Structure of acid-sensing ion channel 1 at 1.9 A resolution and low pH. Nature 2007, 449:316-323.

4. Waldmann R, Champigny G, Bassilana F, Heurteaux C, Lazdunski M: A proton-gated cation channel involved in acid-sensing. Nature 1997, 386:173-177.

5. Wemmie JA, Chen J, Askwith CC, Hruska-Hageman AM, Price MP, Nolan BC, Yoder PG, Lamani E, Hoshi T, Freeman JH, Welsh MJ: The acid-activated ion channel ASIC contributes to synaptic plasticity, learning, and memory. Neuron 2002, 34:463-477.

6. Zha XM, Costa V, Harding AMS, Reznikov L, Benson CJ, Welsh MJ: ASIC2 Subunits Target Acid-Sensing lon Channels to the Synapse via an Association with PSD-95. J Neurosci 2009, 29:8438-8446.

7. Zha XM, Wemmie JA, Green SH, Welsh MJ: Acid-sensing ion channel 1a is a postsynaptic proton receptor that affects the density of dendritic spines. Proc Natl Acad Sci USA 2006, 103:16556-16561.

8. Coryell MW, Ziemann AE, Westmoreland PJ, Haenfler JM, Kurjakovic Z Zha XM, Price M, Schnizler MK, Wemmie JA: Targeting ASIC1a Reduces Innate Fear and Alters Neuronal Activity in the Fear Circuit. Biol Psychiatry 2007, 62:1140-1148.

9. Wemmie JA, Coryell MW, Askwith CC, Lamani E, Leonard AS, Sigmund CD, Welsh MJ: Overexpression of acid-sensing ion channel 1a in transgenic mice increases acquired fear-related behavior. Proc Natl Acad Sci USA 2004, 101:3621-3626.

10. Wemmie JA, Askwith CC, Lamani E, Cassell MD, Freeman JH, Welsh MJ: Acid-sensing ion channel 1 is localized in brain regions with high synaptic density and contributes to fear conditioning. J Neurosci 2003, 23:5496-5502.

11. Xiong ZG, Zhu XM, Chu XP, Minami M, Hey J, Wei WL, MacDonald JF, Wemmie JA, Price MP, Welsh MJ, Simon RP: Neuroprotection in ischemia: blocking calcium-permeable acid-sensing ion channels. Cell 2004, 118:687-698

12. Gao J, Duan B, Wang DG, Deng XH, Zhang GY, Xu L, Xu TL: Coupling between NMDA Receptor and Acid-Sensing lon Channel Contributes to Ischemic Neuronal Death. Neuron 2005, 48:635-646.

13. Friese MA, Craner MJ, Etzensperger R, Vergo S, Wemmie JA, Welsh MJ, Vincent A, Fugger L: Acid-sensing ion channel-1 contributes to axonal degeneration in autoimmune inflammation of the central nervous system. Nat Med 2007, 13:1483-1489.

14. Arias RL, Sung ML, Vasylyev D, Zhang MY, Albinson K, Kubek K, Kagan N, Beyer C, Lin Q, Dwyer JM, Zaleska MM, Bowlby MR, Dunlop J, Monaghan M: Amiloride is neuroprotective in an MPTP model of Parkinson's disease. Neurobiol Dis 2008

15. Ziemann AE, Schnizler MK, Albert GW, Severson MA, Howard lii MA, Welsh MJ, Wemmie JA: Seizure termination by acidosis depends on ASIC1a. Nat Neurosci 2008, 11:816-822.

16. Mazzuca M, Heurteaux C, Alloui A, Diochot S, Baron A, Voilley N, Blondeau N, Escoubas P, Gelot A, Cupo A, Zimmer A, Zimmer AM, Eschalier A, Lazdunski M: A tarantula peptide against pain via ASIC1a channels and opioid mechanisms. Nat Neurosci 2007, 10:943-945.

17. Duan $B, W u L, Y u Y Q$, Ding $Y$, Jing $L, X u L$, Chen J, Xu TL: Upregulation of acid-sensing ion channel ASIC1a in spinal dorsal horn neurons contributes to inflammatory pain hypersensitivity. J Neurosci 2007 27:11139-11148.

18. Chu XP, Close N, Saugstad JA, Xiong ZG: ASIC1a-specific modulation of acid-sensing ion channels in mouse cortical neurons by redox reagents. J Neurosci 2006, 26:5329-5339.

19. Chu XP, Wemmie JA, Wang WZ, Zhu XM, Saugstad JA, Price MP, Simon RP, Xiong ZG: Subunit-dependent high-affinity zinc inhibition of acid-sensing ion channels. J Neurosci 2004, 24:8678-8689.

20. Askwith CC, Cheng C, Ikuma M, Benson C, Price MP, Welsh MJ: Neuropeptide FF and FMRFamide potentiate acid-evoked currents from sensory neurons and proton-gated DEG/ENaC channels. Neuron 2000, 26:133-141.

21. Cho JH, Askwith CC: Potentiation of acid-sensing ion channels by sulfhydryl compounds. Am J Physiol Cell Physiol 2007, 292:C2161-2174.

22. Sherwood TW, Askwith CC: Dynorphin opioid peptides enhance acidsensing ion channel 1a activity and acidosis-induced neuronal death. J Neurosci 2009, 29:14371-14380.

23. Paukert M, Babini E, Pusch M, Grunder S: Identification of the Ca2+ blocking site of acid-sensing ion channel (ASIC) 1: implications for channel gating. J Gen Physiol 2004, 124:383-394.
24. Zha XM, Wang R, Collier DM, Snyder PM, Wemmie JA, Welsh MJ: Oxidant regulated inter-subunit disulfide bond formation between ASIC1a subunits. Proc Natl Acad Sci USA 2009, 106:3573-3578.

25. Xu J, Xia J: Structure and function of PICK1. Neurosignals 2006, 15:190-201.

26. Xia J, Zhang X, Staudinger J, Huganir RL: Clustering of AMPA receptors by the synaptic PDZ domain-containing protein PICK1. Neuron 1999, 22:179-187.

27. Steinberg JP, Takamiya K, Shen Y, Xia J, Rubio ME, Yu S, Jin W, Thomas GM, Linden DJ, Huganir RL: Targeted in vivo mutations of the AMPA receptor subunit GluR2 and its interacting protein PICK1 eliminate cerebellar long-term depression. Neuron 2006, 49:845-860.

28. Gardner SM, Takamiya K, Xia J, Suh JG, Johnson R, Yu S, Huganir RL: Calcium-permeable AMPA receptor plasticity is mediated by subunitspecific interactions with PICK1 and NSF. Neuron 2005, 45:903-915.

29. Xia J, Chung HJ, Wihler C, Huganir RL, Linden DJ: Cerebellar long-term depression requires PKC-regulated interactions between GluR2/3 and PDZ domain-containing proteins. Neuron 2000, 28:499-510.

30. Dev KK, Nishimune A, Henley JM, Nakanishi S: The protein kinase C alpha binding protein PICK1 interacts with short but not long form alternative splice variants of AMPA receptor subunits. Neuropharmacology 1999, 38:635-644.

31. Perez JL, Khatri L, Chang C, Srivastava S, Osten P, Ziff EB: PICK1 targets activated protein kinase Calpha to AMPA receptor clusters in spines of hippocampal neurons and reduces surface levels of the AMPA-type glutamate receptor subunit 2. J Neurosci 2001, 21:5417-5428.

32. Kim CH, Chung HJ, Lee HK, Huganir RL: Interaction of the AMPA receptor subunit GluR2/3 with PDZ domains regulates hippocampal long-term depression. Proc Natl Acad Sci USA 2001, 98:11725-11730.

33. Terashima A, Cotton L, Dev KK, Meyer G, Zaman S, Duprat F, Henley JM, Collingridge $\mathrm{GL}$, Isaac JT: Regulation of synaptic strength and AMPA receptor subunit composition by PICK1. J Neurosci 2004, 24:5381-5390.

34. Xiao N, Kam C, Shen C, Jin W, Wang J, Lee KM, Jiang L, Xia J: PICK1 deficiency causes male infertility in mice by disrupting acrosome formation. J Clin Invest 2009, 119:802-812.

35. Peter BJ, Kent HM, Mills IG, Vallis Y, Butler PJ, Evans PR, McMahon HT: BAR domains as sensors of membrane curvature: the amphiphysin BAR structure. Science 2004, 303:495-499.

36. Jin W, Ge WP, Xu J, Cao M, Peng L, Yung W, Liao D, Duan S, Zhang M, Xia J: Lipid binding regulates synaptic targeting of PICK1, AMPA receptor trafficking, and synaptic plasticity. J Neurosci 2006, 26:2380-2390.

37. Pan L, Wu H, Shen C, Shi Y, Jin W, Xia J, Zhang M: Clustering and synaptic targeting of PICK1 requires direct interaction between the PDZ domain and lipid membranes. Embo J 2007, 26:4576-4587.

38. Duggan A, Garcia-Anoveros J, Corey DP: The PDZ domain protein PICK1 and the sodium channel $\mathrm{BNaC} 1$ interact and localize at mechanosensory terminals of dorsal root ganglion neurons and dendrites of central neurons. J Biol Chem 2002, 277:5203-5208.

39. Hruska-Hageman AM, Wemmie JA, Price MP, Welsh MJ: Interaction of the synaptic protein PICK1 (protein interacting with C kinase 1) with the non-voltage gated sodium channels BNC1 (brain Na+ channel 1) and ASIC (acid-sensing ion channel). Biochem J 2002, 361:443-450.

40. Baron A, Deval E, Salinas M, Lingueglia E, Voilley N, Lazdunski M: Protein kinase $C$ stimulates the acid-sensing ion channel ASIC2a via the PDZ domain-containing protein PICK1. J Biol Chem 2002, 277:50463-50468.

41. Leonard AS, Yermolaieva O, Hruska-Hageman A, Askwith CC, Price MP, Wemmie JA, Welsh MJ: CAMP-dependent protein kinase phosphorylation of the acid-sensing ion channel-1 regulates its binding to the protein interacting with C-kinase-1. Proc Natl Acad Sci USA 2003, 100:2029-2034.

42. Kadurin I, Golubovic A, Leisle L, Schindelin H, Grunder S: Differential effects of $\mathrm{N}$-glycans on surface expression suggest structural differences between the acid-sensing ion channel (ASIC) 1a and ASIC1b. Biochem $J$ 2008, 412:469-475

43. Helenius A, Aebi M: Roles of N-linked glycans in the endoplasmic reticulum. Annu Rev Biochem 2004, 73:1019-1049.

44. Yermolaieva O, Leonard AS, Schnizler MK, Abboud FM, Welsh MJ: Extracellular acidosis increases neuronal cell calcium by activating acidsensing ion channel 1a. Proc Natl Acad Sci USA 2004, 101:6752-6757.

45. Sherwood TW, Askwith CC: Endogenous arginine-phenylalanine-amiderelated peptides alter steady-state desensitization of ASIC1a. J Biol Chem 2008, 283:1818-1830. 
46. Sluka KA, Winter OC, Wemmie JA: Acid-sensing ion channels: A new target for pain and CNS diseases. Curr Opin Drug Discov Devel 2009, 12:693-704.

47. Xiong ZG, Chu XP, Simon RP: Acid sensing ion channels-novel therapeutic targets for ischemic brain injury. Front Biosci 2007, 12:1376-1386

48. Anzai N, Deval E, Schaefer L, Friend V, Lazdunski M, Lingueglia E: The multivalent PDZ domain-containing protein CIPP is a partner of acidsensing ion channel 3 in sensory neurons. J Biol Chem 2002, 277:16655-16661.

49. Hruska-Hageman AM, Benson CJ, Leonard AS, Price MP, Welsh MJ: PSD-95 and Lin-7b interact with acid-sensing ion channel-3 and have opposite effects on H+- gated current. J Biol Chem 2004, 279:46962-46968.

50. Torres GE, Yao WD, Mohn AR, Quan H, Kim KM, Levey Al, Staudinger J, Caron MG: Functional interaction between monoamine plasma membrane transporters and the synaptic PDZ domain-containing protein PICK1. Neuron 2001, 30:121-134

51. Chung HJ, Xia J, Scannevin RH, Zhang X, Huganir RL: Phosphorylation of the AMPA receptor subunit GluR2 differentially regulates its interaction with PDZ domain-containing proteins. J Neurosci 2000, 20:7258-7267.

52. Williams ME, Wu SC, McKenna WL, Hinck L: Surface expression of the netrin receptor $\mathrm{UNC5H} 1$ is regulated through a protein kinase Cinteracting protein/protein kinase-dependent mechanism. J Neurosci 2003, 23:11279-11288.

doi:10.1186/1756-6606-3-39

Cite this article as: Jin et al:: PICK1 regulates the trafficking of ASIC1a and acidotoxicity in a BAR domain lipid binding-dependent manner. Molecular Brain 2010 3:39.

\section{Submit your next manuscript to BioMed Central and take full advantage of:}

- Convenient online submission

- Thorough peer review

- No space constraints or color figure charges

- Immediate publication on acceptance

- Inclusion in PubMed, CAS, Scopus and Google Scholar

- Research which is freely available for redistribution

Submit your manuscript at www.biomedcentral.com/submit 